\title{
Para além das fronteiras: o particular e o cultural nas cartas de Casais Monteiro e Ribeiro Couto
}

[ Beyond the frontiers: the particular and the cultural in the letters of Casais Monteiro and Ribeiro Couto

\section{Mirhiane Mendes de Abreu ${ }^{\mathrm{I}}$}

LEITE, Rui Moreira (Org.). Correspondência - Casais Monteiro e Ribeiro Couto. São Paulo: Editora Unesp, 2016.

Adolfo Casais Monteiro (I898-I963) e Rui Ribeiro Couto (I908-I972) corresponderamse por décadas. $\mathrm{O}$ acesso a esse diálogo está hoje disponível graças à organização

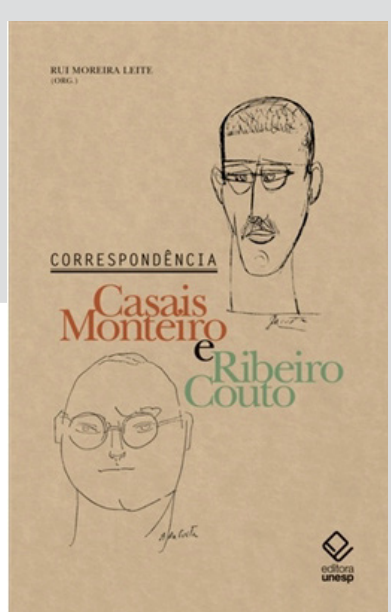
de Rui Moreira Leite, que percorreu diversos arquivos pessoais para oferecer ao público a sustentação de uma profícua amizade, registrada em I25 documentos produzidos entre 22 de junho de I93I e 30 de maio de I962. A esse conjunto, anexou ainda dois documentos de Ribeiro Couto (um ofício encaminhado ao Serviço de Cooperação Internacional do Itamaraty e uma carta passiva de Múcio Leão), uma entrevista de Casais Monteiro à revista portuguesa Árvore, um discurso não proferido de Cecília Meireles por ocasião de conturbada premiação pela Academia Brasileira de Letras e reproduções fac-similares de várias imagens de livros com dedicatórias de um ao outro e também a terceiros. Trazida a lume pela Editora da Unesp em 20I6, essa correspondência coloca o leitor diante do processo formativo de dois intelectuais, um português e um brasileiro, e dos temas inerentes ao cenário cultural transatlântico.

ABREU, Mirhiane Mendes de. Para além das fronteiras: o particular e o cultural nas cartas de Casais Monteiro e Ribeiro Couto. Revista do Instituto de Estudos Brasileiros, Brasil, n. 67, p. 222-228, ago. 2017.

DOI: http://dx.doi.org/Io.II606/issn.23I6-90IX.voi67p222-228

I Universidade Federal de São Paulo (Unifesp, São Paulo, SP, Brasil). 
Na primeira metade do século XX, as chamadas políticas luso-brasileiras de estreitamento de laços se concretizaram em programas, acordos e tratados, os quais almejavam avizinhar econômica e culturalmente os dois países. Quando vista pela correspondência pessoal de intelectuais - isto é, afastada do âmbito institucional e protocolar -, essa proximidade é uma experiência singularizada, mas acaba por produzir efeitos na esfera pública. Firmado na troca de cartas, o vínculo afetivo entre Casais Monteiro e Ribeiro Couto caracteriza-se com este balanço: movimenta-se do pessoal ao público com consequências culturais marcantes para os dois lados. Isso pode ser percebido retrospectivamente a partir de um exemplo concreto. Em I972, o Instituto de Estudos Brasileiros da Universidade de São Paulo (IEB/USP) publicou postumamente o livro Figuras e problemas da literatura brasileira contemporânea, de autoria de Casais Monteiro ${ }^{2}$. Assíduo leitor da nossa literatura, mais do que seu mero promotor cultural, o escritor português constituiu-se crítico das letras brasileiras e investiu nessa atividade um exercício intelectual cujo processo foi pouco a pouco estabelecido pelo diálogo estreito com Ribeiro Couto, conforme lemos na dedicatória do livro citado:

À memória de Ribeiro Couto - porque das suas mãos, antes ainda de nos conhecermos, veio a oferta dos livros de Manuel Bandeira e de Carlos Drummond de Andrade, que, com os seus, foram o ponto de partida do interesse que desde então, mais de vinte anos antes de vir para o Brasil, sempre teve para mim a literatura deste país. Mas sobretudo porque o homem cordial por excelência que foi Ribeiro Couto desvendou para mim uma realidade, foi o ponto de partida duma experiência humana que tornou profético aquele verso que não posso lembrar sem emoção, quando, no poema Correspondência de Família, me dizia:/ "Com que amor pisarás um dia a terra da nova Nação."/ Ao amigo inesquecível, a homenagem deste livro é pobre testemunho duma gratidão que as minhas palavras não sabem exprimir³.

Uma visão de causa e efeito se enuncia nessa dedicatória e sublinha o papel

2 MONTEIRO, Adolfo Casais. Figuras e problemas da literatura brasileira contemporânea. São Paulo: IEB, I972.

3 Ibidem (grifos meus). 
relevante da amizade entre eles quer para a vida em geral, quer para as atividades críticas em particular de Casais Monteiro, as quais ganharam terreno fértil no âmbito privado da correspondência. O diálogo epistolar entre os dois significou um mecanismo de experimentação cultural e crítico-literária, anunciada desde a primeira carta da série que se encontra no volume, com declarações do seguinte teor: "a sua poesia foi para mim uma revelação imensa" (p. 30); "a sua poesia está tão próxima de mim, e não tanto de minha poesia, mas duma maneira de ser [...]" (p. 30); ou ainda "encontro afinidade consigo" (p. 3I). Ao lado dessas declarações, o missivista analisa o "aspecto descritivo" dos poemas do amigo e conclui: "O Ribeiro Couto descreve como eu quereria descrever" (p. 3I). Salta aos olhos na leitura que se segue o entusiasmo do então jovem português com o diálogo concedido pelo já diplomata e poeta Ribeiro Couto. Tal entusiasmo dá lugar ainda a dois outros interesses: a literatura brasileira contemporânea e a revista presença, cujas páginas, oscilando entre o provincianismo e o cosmopolitismo, estampavam obras e estudos de autores de diversos lugares do mundo, incluindo o Brasil4.

Além da presença, inúmeros periódicos são mencionados nesse diálogo epistolar, a saber: Atlântida, Boletim de Ariel, Lanterna Verde, Le Journal des Poètes, Mundo Literário, Portucale, Revista de Portugal, Seara Nova, para citarmos apenas os mais referidos. Como se sabe, a produção de periódicos propiciou formulações estéticas no contexto de efervescência cultural dos anos de I920 no Brasil, em Portugal e no mundo e se tornou prática contínua nos anos subsequentes. As revistas sistematizavam o que se compreendia como procedimento artístico, arregimentavam colaboradores afinados com o ideário proposto e tornavam disponíveis produções artísticas. Ainda que esses dispositivos fossem desiguais (tanto por acabamento formal, quanto por divergência de concepções estéticas e culturais), a adesão às diretrizes programáticas de um grupo se fazia sentir pelos editoriais esboçados muitas vezes aos moldes de manifestos. Entre Casais Monteiro e Ribeiro Couto, os periódicos da ocasião, mesclados a quaisquer outros assuntos, foram o tema mais assíduo de apreciação, fosse pelo aspecto gráfico, fosse por força de eventuais colaborações, fosse até por circunstâncias financeiras, notadamente no que dizia respeito à revista presença. Diante disso, cabe uma observação: na primeira metade do século XX, cartas e revistas exerciam função seminal e pronunciavam-se igualmente como atividades culturais agregadoras. O exame de periódicos modernistas nos expõe um gênero multiforme, capaz de abrigar poemas, contos, fragmentos de romances e peças teatrais, ensaios, imagens, notícias, propagandas e outros. Essa também é a feição da correspondência e muito particularmente da correspondência que temos em mãos, a de Ribeiro Couto e Casais Monteiro. Os correspondentes, mergulhados nessa pluralidade discursiva, viviam sob o signo de uma modernidade (ainda que periférica) e exprimiam os modos como foram construídos e dissolvidos os pares

4 Expondo as limitações da vivência da vanguarda em Portugal, Fernando Cabral Martins analisa o papel da revista presença, periódico que, segundo o estudioso, exprimiu “a própria impossibilidade de continuação da Vanguarda" e que apostou no "regresso às formas e gêneros que correspondem a um paradigma anterior à convulsão daquilo a que José Régio dá o nome de Modernismo". MARTINS, Fernando C. Mário Cesariny e O virgem negra. Lisboa: Documenta, 20I6, p. 27. 
opositivos nacional/estrangeiro e centro/periferia, elementos com os quais se urdiu o tecido da modernidade nos dois países.

Quanto ao gênero, revistas e cartas aproximam-se pelo caráter multiforme. E afastam-se por uma particularidade: aquelas são públicas; estas, pessoais. No entanto, mesmo essa pessoalidade se traduz, em alguns casos, em caráter gregário, o que ocorre quando determinado exemplar adquire a feição de carta circular ${ }^{5}$, destinando-se a uma pequena e selecionada pluralidade de leitores. Assim, Casais Monteiro alude à admiração estética que, como ele próprio, Ribeiro Couto nutria por Jules Supervielle e Léon-Paul. E sabia disso porque "o Gaspar Simões leu-me algumas de suas cartas” (p. 30). Salta aos olhos, na continuidade dessa declaração, que o registro epistolar desenha também a formação intelectual e poética de cada um deles no que esse processo possui de individual e de partilha. É o que registra Ribeiro Couto numa carta:

Releio (uma vez ainda) tudo o que me diz a propósito da sua formação. Da sua revelação poética. Todos estes nomes que v. cita, José Régio (que grande poeta!), Mário de SáCarneiro, Fernando Pessoa - dois mestres admiráveis, e que pena que o primeiro se tenha acabado tão tristemente! - são familiares à minha alma graças ao João Gaspar Simões. (Mário de Sá-Carneiro, estou à espera da publicação das obras completas, anunciadas pela presença). Porém, dos três é o que conheço menos. O Fernando Pessoa, de quem Jules Supervielle me falava há dias com tanta admiração, é um dos casos europeus mais notáveis. Tenho lido na presença tudo que, sob quatro assinaturas diversas, ele publicou ali” (p. 36).

Contemporaneidade: eis o que interessava a cada um dos missivistas. De um lado, consideravam as respectivas produções literárias; de outro, debatiam sobre os escritores identificados sob o signo da modernidade. A meu ver, é desse ponto de vista que decorre a proximidade intelectual entre eles e, genericamente, entre a produção cultural portuguesa e a brasileira daqueles anos. Quando percorremos esse diálogo epistolar, notamos facilmente as coincidências de leituras que se tornaram ativas como atividades críticas tanto de Ribeiro Couto, quanto de Casais Monteiro. E nisso residem o gosto e a reflexão que ambos cultivaram pelas obras de Manuel Bandeira e António Nobre, sobre os quais discutiram procedimentos estilísticos e formas de análise. Além disso, a revista presença publicou cartas inéditas de António Nobre organizadas por Casais Monteiro e seus estudos sobre Ribeiro Couto, Bandeira,

5 A matéria epistolar tem sido objeto de reflexão e sistemático exame investigativo. No contexto teórico, Geneviève Haroche-Bouzinac aborda, dentre outros aspectos, a "variedade das formas", isto é, a adaptabilidade de usos e formatos como uma propriedade da carta. Elencando um conjunto de operações do gênero epistolar, a autora trata da "carta circular" como aquela que é dirigida a uma comunidade mais ampla em função do conteúdo e da coesão do grupo. HAROCHE-BOUZINAC, Geneviève. Escritas epistolares. Trad. Ligia Fonseca Ferreira. São Paulo: Edusp, 20I6, p. 54. 
Drummond e Alcântara Machado, segundo se depreende das notas elucidativas que o organizador acrescenta a essa correspondência ${ }^{6}$.

Ressalvadas as particularidades críticas de cada um dos correspondentes, Ribeiro Couto e Casais Monteiro coincidem no exame estético do tempo que lhes era atual: "Gostaria de dedicar um livro inteiro à literatura actual do Brasil" (p. 75), afirma o português, privilegiando, assim, o momento presente. A convergência desses interesses indicia uma tendência forte nesse diálogo e na poética que produziram. Por caminhos pessoais ou mais gregários, ambos chegaram à fundamental perspectiva: tornar-se intelectual do próprio tempo equivalia a fazer o presente cultural conhecido por informações providas em cartas, estampadas em revistas e revolvidas em exames investigativos. Inversamente, divergem quanto aos posicionamentos políticos, os quais, por fim, acabam por afastá-los, embora o diálogo seja posteriormente retomado. No rastreamento dessa correspondência, porém, assistimos às consequências na vida pessoal de Casais Monteiro: prisão, desemprego e, nesse torvelinho, a boa-nova da paternidade. Fase difícil, mas permanentemente assistida pelo generoso amigo brasileiro, que tornou exequível a partida definitiva do estudioso português para o Brasil e a quem forneceu imprescindível colaboração institucional. É como identificamos no ofício encaminhado por ele ao Serviço de Cooperação Internacional do Itamaraty datado a 3 de setembro de I937, onde se lê: "Tudo isso me leva a recomendar a Vossa Excelência, com especial empenho, o Sr. Adolfo Casais Monteiro, para que o Serviço de Cooperação Intelectual, se possível, lhe remeta tudo que seja aconselhável entre as publicações poéticas de nosso país" (p. 288).

Do ângulo pessoal ao público, do descontraído ao institucional, os dois escritores aqui examinados pela correspondência aproximaram-se por suas atitudes intelectuais organizadas entre a partilha e a reflexão. Poetas do tempo presente, as cartas mostram que ambos olharam para a atualidade e fizeram desse encontro epistolar um instrumento de aproximação e formulação do que os inquietava intelectualmente. Buscavam o atual, mas não deixaram de ser brasileiro e português, condição indispensável na manutenção e nos efeitos do vínculo.

A reciprocidade intelectual entre brasileiros e portugueses da primeira metade do século XX vem sendo objeto de exame e discussão por parte da crítica literária, como se pode perceber pelo trabalho de Claudia Poncioni e Virgínia Camilotti, que organizaram a correspondência entre João do Rio e João de Barros no livro Muito d'alma: cartas de Paulo Barreto (João do Rio) a João de Barros?. Tania Martuscelli, em [Des]conexões entre Portugal e o Brasil - séculos XIX e XX, propõe uma discussão dessa proximidade intelectual pelo espaço das revistas no âmbito dos estudos culturais ${ }^{8}$. Em Modernismo brasileiro e modernismo português, Arnaldo Saraiva realizou o

6 Além das notas que completam as informações das cartas, o organizador acrescentou também uma imagem com a primeira página do ensaio “A mensagem do lusíada António Nobre”, estudo de Ribeiro Couto sobre o poeta português publicado na revista lisboeta Litoral (p. 4I, 52 e I95).

7 PONCIONI, Claudia; CAMILOTTI, Virgínia. Muito d’alma: cartas de Paulo Barreto (João do Rio) a João de Barros - I909 a I92I. Rio de Janeiro: Academia Brasileira de Letras/Garamond, 2015.

8 MARTUSCELLI, Tania. [Des]conexões entre Portugal e Brasil - séculos XIX e XX. Lisboa: Colibri, 2016. 
levantamento e a divulgação de documentos até há pouco inéditos, que colaboram para elucidar as relações culturais e literárias entre Brasil e Portugal naqueles anos9. Estudos monográficos, artigos e teses acadêmicas têm contribuído para o aprofundamento do debate sobre o tema. A bibliografia sobre as relações entre os dois países é crescente e permite perceber a construção de um campo cultural comum, formado por trocas efetuadas por meios diversos, de que as cartas entre Casais Monteiro e Ribeiro Couto se mostram partícipes.

A Correspondência - Casais Monteiro er Ribeiro Couto, soma-se à bibliografia sobre as proximidades culturais entre os dois países. Incide também sobre a revitalização da prática analítica da crítica literária contemporânea, notadamente quanto ao manuseio de fontes primárias - a exemplo das cartas - conservadas em arquivos pessoais abrigados em instituições e universidades. Não se trata apenas de reunir uma massa informe de documentos, mas de organizar criticamente como se pode operar a leitura de um específico diálogo epistolar. Nessa organização, constitui-se o processo de anotação, que irá conduzir o raciocínio crítico e interpretativo do leitor. Do ponto de vista teórico-metodológico, Colette Becker, considerando o grau de subjetividade do crítico-organizador, reconhece no conteúdo da anotação o rumo da leitura e a construção do público ao qual a nota se dirige ${ }^{\mathrm{Io}}$. Essa observação é relevante porque muitos editores de correspondência evitam sobrecarregar seus volumes com notas, o que evidencia uma opção crítica. Rui Moreira Leite fez sua escolha, e ela foi, por assim dizer, minimalista: admitiu o valor de algumas informações preponderantemente bibliográficas a fim de completar o sentido das cartas e as anotou. A posição-chave do organizador acerca da matéria interpretativa foi aglutiná-la em forma de apresentação, na qual expôs os quatro momentos cronológicos desse diálogo epistolar, deles extraindo o timbre temático. Em síntese, na edição preparada por Moreira Leite, a convergência das notas e da apresentação exerce funcionamento na leitura do diálogo epistolar e postula uma concepção crítica e analítica sobre os modos de editar e ler correspondências pessoais.

Como resultado, podemos acompanhar uma conversa transatlântica, por meio da qual Ribeiro Couto e Casais Monteiro transgrediram muitos lugares-comuns. Criadores e leitores críticos, ambos demonstraram, em suas cartas, que o indispensável para a preservação de um diálogo intercultural tão longevo não é nem o protocolo, nem um relacionamento desigual pautado por índices de fonte e influência. Parece-me digno observar que a sustentação dessa amizade culturalmente operacional entre um intelectual brasileiro e um português deve-se ao registro epistolar, através do qual ambos superaram as fronteiras geográficas, culturais, etárias e ideológicas. Materializado nas cartas, o diálogo entre eles fez com que um repertório pessoal e subjetivo se concretizasse como página incontornável da história da cultura dos dois países.

9 SARAIVA, Arnaldo. Modernismo brasileiro e modernismo português. Subsídios para o seu estudo e para a história das suas relações. Campinas: Editora Unicamp, 2004.

Io BECKER, Colette. O discurso de escolta: as notas e seus problemas. Trad. Ligia Fonseca Ferreira. In: Patrimônio e Memória, v. 9, n. I. Assis: Unesp, 2013. 


\section{MIRHIANE MENDES DE ABREU é professora}

adjunta de Literatura Brasileira da Universidade

Federal de São Paulo (Unifesp).

E-mail: mirhiane.abreu@unifesp.br

\section{REFERÊNCIAS BIBLIOGRÁFICAS}

BECKER, Colette. O discurso de escolta: as notas e seus problemas. Trad. Ligia Fonseca Ferreira. In: Patrimônio e Memória, v. 9, n. I. Assis: Unesp, 2013.

HAROCHE-BOUZINAC, Geneviève. Escritas epistolares. Trad. Ligia Fonseca Ferreira. São Paulo: Edusp, 2016. MARTINS, Fernando C. Mário Cesariny e O virgem negra. Lisboa: Documenta, 2016.

MARTUSCELLI, Tânia. [Des]conexões entre Portugal e Brasil - séculos XIX e XX. Lisboa: Colibri, $20 I 6$.

MONTEIRO, Adolfo Casais. Figuras e problemas da literatura brasileira contemporânea. São Paulo: IEB, I972. PONCIONI, Claudia; CAMILOTTI, Virgínia. Muito d'alma: cartas de Paulo Barreto (João do Rio) a João de Barros - I909 a I92I. Rio de Janeiro: Academia Brasileira de Letras/Garamond, 2015.

SARAIVA, Arnaldo. Modernismo brasileiro e modernismo português. Subsídios para o seu estudo e para a história das suas relações. Campinas: Editora Unicamp, 2004. 